\section{Will the advances in our understanding of mucosal immunology contribute to improvements in clinical control of IBD?}

There has been rapid progress in our understanding of mucosal immunology, especially in the gut. Intensive research has recently (i) demonstrated the importance of Thelper type 17 cell (Th17) immunity, as a new paradigm, in the pathogenesis of chronic inflammatory disorders; ${ }^{1}$ (ii) identified several subpopulations of intestinal antigenpresenting cells that control gut homeostasis and inflammation; ${ }^{2}$ (iii) identified a new immune cell population, lymphoid tissue inducer-like cells; ; ${ }^{3}$ (iv) demonstrated the importance of microorganisms (for example, segmented filamentous bacteria) for host immune system development; ${ }^{4}$ and (v) demonstrated the important role of autophagy in bacterial elimination in the gut. 5

Since the identification of NOD2 as a susceptibility gene for Crohn's disease in 2001, innate immunity in the gut has been highlighted in the pathogenesis of inflammatory bowel disease (IBD). A genome-wide association study has since identified many more IBD susceptibility genes. ${ }^{6}$ Among them, the association of several genes in the interleukin-23-Th17 axis or those involved in autophagy with IBD provides strong evidence for the importance of abnormal innate immune responses in IBD pathogenesis. ${ }^{7,8}$

However, we should also recognize that we still have an incomplete picture. Although the identification of NOD2 was a landmark moment in mucosal immunology and IBD research, we are still awaiting the revelation of how its abnormal function causes Crohn's disease. Following the discovery of $N O D 2$, a plethora of suspects have emerged as possible protagonists in the mystery of IBD, making it rather difficult to identify the responsible party.

With all the recent progress in our understanding of mucosal immunology, one question remains: is it likely to contribute to better management of IBD in the clinic? The success of infliximab - the tumor necrosis factor- $\alpha$ (TNF- $\alpha$ ) antibody hailed as a miracle medicine-is beyond any doubt. Before the first report of clinical use of this drug, several basic reports demonstrated an increased level of TNF- $\alpha$ in the mucosa and stools of patients with Crohn's disease. Certainly, the TNF- $\alpha$ antibody story is often cited as a successful case of translational research between basic immunology and the clinic. However, we believe that the passion of the clinicians and the decisions they made in saving a 12-year-old girl were also essential to the success of this miracle medicine. ${ }^{9}$ At that time, there was insufficient evidence to support the use of TNF- $\alpha$ antibodies in the treatment of Crohn's disease. From a different point of view, the clinical success of the TNF- $\alpha$ antibody encouraged basic research into mucosal immunology.

The TNF- $\alpha$ antibody and other developing biologics will improve the quality of life of IBD patients. Nonetheless, the incidence of IBD is still high and the number of IBD patients is increasing, even in Asian countries. These findings cannot be explained by the alteration of genetic susceptibility. Mucosal immunology research now highlights the association between the host and its intestinal flora, although research into the interactions between humans and their intestinal flora is still ongoing.

As Hayday and Peakman suggested in a recent review, ${ }^{10}$ human mucosal immunology research has "run up against a wall." Most of the high-quality papers present results from mouse studies, and discussion of the pathogenesis of human disease is often based on information gleaned entirely from the findings in murine studies. Certainly, knockout animals are a powerful tool with which to identify the function of a target molecule; however, the findings in mice are often inconsistent with human disease. To ensure the success of translational research in the field of mucosal immunology in the gut, several problems need to be addressed, including the inadequacy of the funding support system for relevant human studies. Most importantly, communication between basic immunologists and clinicians (or physician scientists) must be enhanced. A deeper mutual understanding will help to break down this wall.

We should be optimistic-we currently have a large number of candidate molecules to study, ${ }^{11}$ genetic information, and new technologies at our disposal for research into IBD. We can confidently expect that the recent advances in our understanding of mucosal immunology will contribute to the development of new drugs for IBD, uncover its etiology, and lead to the prevention of disease development. There is still a long way to go, but cracks in the wall are developing.

\section{Tadakazu Hisamatsu \\ Toshifumi Hibi, Member, \\ Executive Advisory Board}

(C) 2011 Society for Mucosal Immunology

1. Tesmer, L.A., Lundy, S.K., Sarkar, S. \& Fox DA. Th17 cells in human disease. Immunol. Rev. 223, 87-1113 (2008).

2. Atarashi, K. et al. ATP drives lamina propria $T(H) 17$ cell differentiation. Nature 455, 808-812 (2008).

3. Colonna, M. Interleukin-22-producing natural killer cells and lymphoid tissue inducer-like cells in mucosal immunity. Immunity 31, 15-23 (2009).

4. Ivanov, A.K. II et al. Induction of intestinal Th17 cells by segmented filamentous bacteria. Cell 139 , 485-498 (2009).

5. Rioux, J.D. et al. Genome-wide association study identifies new susceptibility loci for Crohn disease and implicates autophagy in disease pathogenesis. Nat. Genet. 39, 596-604 (2007).

6. Budarf, M.L., Labbé, C., David, G.. \& Rioux, J.D. GWA studies: rewriting the story of IBD. Trends Genet. 25, 137-146 (2007).

7. Ahern, P.P., Izcue, A., Maloy, K.J. \& Powrie, F. The interleukin-23 axis in intestinal inflammation Immunol. Rev. 226, 147-159 (2008).

8. Heath, R.J. \& Xavier, R.J. Autophagy, immunity and human disease. Curr. Opin. Gastroenterol. 25 512-520 (2009).

9. Derkx, B. et al. Tumour-necrosis-factor antibody treatment in Crohn's disease. Lancet 342, 173-174 (1993).

10. Hayday, A.C. \& Peakman, M. The habitual, diverse and surmountable obstacles to human immunology research. Nat. Immunol. 9, 575-580 (2008).

11. Melmed, G.Y. \& Targan, S.R. Future biologic targets for IBD: potentials and pitfalls. Nat. Rev. Gastroenterol. Hepatol. 7, 110-117 (2010). 